\title{
Valoración del estado de alteración de los materiales pétreos en los monumentos
}

JOSE M. FERNANDEZ PARIS

Ing. T. Químico y Prof. Numerario de Física. Jefe de la Sección de Ensayos Químicos de INTEMAC

\section{$R E S U M E N$}

Se analiza una falta sistemática, para la realización de ensayos, que permitan establecer las posibles causas que originan la alteración de piedras en los monumentos artisticos. Como resultado, se proponen un conjunto de métodos, adoptados por las normas ASTM $y$ aconsejados por RILEM que permiten en función de unas especificaciones; introducidas por la experiencia, asegurar con un grado aceptable de fiabilidad la situación de durabilidad del elemento pétreo considerado.

\section{$S U M M A R Y$}

\begin{abstract}
Analyzed is a systematic fault, in the carrying out of tests, which permits the establishment of the possible causes which originate the alteration of stones in artistic monuments. As a resut, a collection of methods is proposed, adopted by the ASTM standards and recommended by the RILEM, which permit the functioning of some specifications, introduced by the experiment, to assure an acceptable degree of durability of the petrous element considered.
\end{abstract}

Cuando comencé a pergeñar esta conferencia premedité un esquema que adolecía, como la mayor parte de los trabajos que tratan de la alteración de los elementos pétreos en monumentos, de ampulosas explicaciones sobre el llamado "mal de la piedra", considerándole como un cáncer motivado por la contaminación del medio ambiente.

Ambas ideas - cáncer y contaminación-, debido a su carácter funesto y fatalista, llevan garantizando el éxito y la atención del auditorio; pero también es cierto que los escritos sobre el tema, al menos la mayoría, carecen de ideas concretas y de auténticas directrices que conduzcan a planes de ensayos sistemáticos.

Este confusionismo, en el cual me he visto sumergido cada vez que he comenzado un estudio de un monumento determinado, se ha ido desvelando, cuando al ejecutar los estudios precisaba de nuevos ensayos, que poco a poco fueron configurando lo que posteriormente sería para mi una forma sistemática de actuación.

Trataré de explicar la razón de ser de este Plan de Ensayos que, debo anteponer, van encaminados a conocer y valorar el estado en que se encuentran las distintas zonas pétreas de un edificio, desde el punto de vista estructural, y no a la capacidad de restauración de un motivo ornamental o grupos escultóricos de fachadas, ventanales o frisos.

Estoy convencido de que un artista disfrutaría más oyendome hablar de las figuras esculpidas en las archivoltas, tímpanos y jambas; de la situación de los arcos ojivales en las ventanas o de las tracerías de las galerías. Pero no va a ser así, he preferido dar un golpe de timón y seguir por nuevos derroteros, que posiblemente sean erróneos, más no confusos en su finalidad.

Francis Bacon sentenció que "la verdad podía salir de un error, pero nunca de un confusionismo de ideas". Ojalá que esta disertación sirva para aclarar futuras actuaciones y no 
sean los monumentos en nuestras manos simples cobayas destinados a sucumbir entre remedios y emplastos de curanderos seudocientíficos.

No debemos olvidar que el éxito reside en el conocimiento más exacto posible de los distintos materiales pétreos, conocimiento que el técnico experto en degradaciones de piedra ha de transmitir de forma inteligible al arquitecto o ingeniero sus ideas sobre el futuro comportamiento y su posible inhibición a los daños venideros.

Con el mejor deseo de colaboración en vuestras tareas artísticas de restauración expondré a modo de sugerencias algunos criterios que ayuden a desvelar dudas y resolver problemas.

El arte de la arquitectura es una forma de expresión plástica y cultural en donde los volúmenes suelen materializarse empleando materiales de naturaleza pétrea como elementos durables. Los monumentos arquitectónicos son el reflejo de la cultura de las distintas civilizaciones de la Humanidad.

La durabilidad de las piedras naturales ha sido proverbial, hasta el punto de que los vocablos "piedra" y "roca" se han tomado como sinónimos de resistencia en el lenguaje coloquial, pero la Geología moderna considera que los minerales que componen las rocas están en un contínuo proceso evolutivo, tratando en todo momento de adaptarse a las condiciones del medio ambiente en la superficie de la Tierra.

Una vez más de forma inexorable las leyes de la Termodinámica rigen las reacciones geológicas, transformándose los minerales existentes en otros de mayor estabilidad, frente a la acción del medio ambiente que los rodea.

La alteración de un monumento artístico entraña siempre un problema de degradación de algún material de construcción (piedra, madera, metal o aleación, etc.), que experimenta en su estructura los agentes externos agresivos, produciendo en ellos alteraciones que incluso pueden llegar a destruirlos totalmente.

La agresión de los agentes degradantes se verifica siempre merced a un vehículo que los introduce en el seno del material afectado, estando generalmente presente este vehículo en el medio ambiente atmosférico.

Sería conveniente desterrar el vocablo "patología" para designar las alteraciones de los materiales de construcción. Si la Patología trata de las enfermedades que afectan a los seres vivos, es evidente que algunas tienen curación, es decir, gozan de un principio de reversibilidad, mientras que las reacciones de alteración de un material obedecen a leyes químicas irreversibles, que a lo sumo pueden detenerse.

La mayor parte de las veces su simple conocimiento nos basta para adoptar medidas de conservación o sustitución, pero nunca de curación. Las alteraciones de los materiales son problemas de degradación y "degradación de los materiales", es la expresión más adecuada.

Los procesos de degradación dependen del material intrínsecamente, así como de las condiciones climáticas y ambientales de su entorno. Su estudio abarca el conocimiento de ambos.

En esta disertación se consideran únicamente los materiales de naturaleza pétrea y, como agentes agresivos, la humedad, la oxidación, la atmósfera, el clima y la temida contaminación. 


\section{TIPOS DE PIEDRA}

Los distintos elementos pétreos que integran los monumentos pertenecen a rocas, es decir, a minerales que por su extensión forman parte de la corteza terrestre.

No es momento de repasar las diversas rocas ígneas, sedimentarias y metamórficas, clasificadas por la Geología tradicional, porque el hombre ha buscado siempre la ley del mínimo esfuerzo y por ello ha esculpido y tallado piedras blandas y fáciles de trabajar.

En los distintos estudios que he llevado a cabo he podido observar que el tipo de piedra adoptado no era el más idóneo para la durabilidad que se esperaba, pero generalmente era la más blanda de talla.

Por su aptitud de moldeo las más utilizadas son las piedras calizas y las areniscas, debido a que están constituidas por partículas que durante el proceso de génesis se han ido cementando entre sí.

Las calizas y areniscas suelen ser tanto más adecuadas cuanto menos porosidad y absorción de agua posean, y mayor resistencia mecánica a compresión manifiesten.

La aptitud y valoración de este tipo de piedras se indica en datos del Anejo, de acuerdo con normas ASTM.

Las calizas menos resistentes son las nummulíticas y las oolíticas, debido a su formación por precipitación y deposición.

Un caso típico de alteración de calizas lo constituyen las bóvedas y la cúpula de la Catedral de Cádiz y los capiteles del Claustro de Santo Domingo de Silos.

Notables degradaciones de areniscas se han observado en la Clerecía, Catedral y Pórtico de la Universidad de Salamanca, así como en las Torres de la Catedral de León.

Más resistentes a las agresiones son los mármoles, en realidad rocas calizas sometidas a procesos de metamorfismo, que suelen contener óxidos metálicos que les confieren veteados y jaspeados. Adquieren un bello pulimento y acostumbran a alterarse si están expuestos a la intemperie, e incluso en interiores por acción de humedades y contaminación. Merecen citarse los frisos de la Basílica del Pilar y la Columnata de la Catedral de Cádiz.

Las rocas más durables son las de origen ígneo y en especial, debido a su grano fino, los pórfidos, basaltos y dioritas. Los granitos y sienitas de grano más grueso son más fácilmente descompuestos en partículas, que una vez individualizadas no resisten a los procesos de metereorización.

\section{Condiciones ambientales}

Un dato trascendental, que debe investigarse muy profundamente, mediante una lectura atenta del proceso constructivo del monumento, es la cantera de donde procede la roca empleada.

Las rocas sufren procesos de adaptación en el medio ambiente y cuando se emplean en elementos constructivos alejados de su zona de origen se alteran y degradan, tanto más intensamente, cuanto más dispares sean los factores climatológicos. Por otra parte, durante su transporte a otros lugares las piedras pierden la llamada "agua de cantera" hacién- 
dose más alterables. Los antiguos canteros sabían que una piedra labrada "verde" era más durable, debido a que los materiales pulverulentos y las sales disueltas procedentes de la labra colmataban los poros exteriores, evitando la evaporación del agua de cantena. Si este tipo de agua se pierde por evaporación se verá compensada por la humedad de las lluvias, nieblas o filtraciones del subsuelo.

Un ejemplo de adaptación inadecuada lo constituye el Obelisco Egipcio llevado por Napoleón a la Place Vendome de París, después de sus campañas bélicas. Aquellas piedras soportaron 3.000 años el clima riguroso del país de los faraones y no pudieron soportar 150 en el clima templado de Francia. Razones análogas podríamos aducir de la famosa Aguja de Cleopatra trasladada a la ciudad de New York; pero un caso más reciente, y junto a nosotros lo tenemos en la alteración del Templo de Debod, traido a Madrid en 1971, desde un apartado lugar de Nubia, donde había soportado la acción de 23 siglos, e incluso la inmersión de varios meses cada año bajo las aguas embalsadas en la antigua Presa de Asuán, y después de 11 años en el clima de Madrid, las piedras se deshacen transformándose en un montón de arena.

Una labra inadecuada se empleó en la talla de la piedra caliza para cerrar las bóvedas de la Catedral de Cádiz. La roca procedía de unas canteras sitas en la localidad malaguer̃a de Manilva, y debido a la Guerra de La Independencia estuvieron en el malecón del muelle gaditano, expuestas a la intemperie y a la acción salobre del mar durante más de 25 años.

\section{Acción de los compuestos de hierro}

Una característica química a considerar en una roca es el contenido de compuestos férricos y ferrosos.

El hierro suele incorporarse a una roca en forma de silicatos ferromagnesianos, compuestos piritosos de sulfuro de hierro, tales como pirrotitas y marcasitas, o como carbonato ferroso, llamado siderita.

Los compuestos de hierro confieren a las piedras tonalidades rojizas y pardas, así como veteardos que las hacen más estimables desde el punto de vista estético.

Los minerales de hierro antes mencionados tienen tendencia a captar humedad del medio ambiente y transformarse poco a poco en el mineral llamado "goetita", $\mathrm{FeOOH}$, con daracterísticas amorfas y coloidales, y finalmente en compuestos férricos de carácter expansivo.

Me parece conveniente profundizar en el comportamiento del hierro, pues en su estudio he hallado la base para conocer el grado de durabilidad y estado de alteración de bastantes rocas.

Los compuestos piritosos suelen estar presentes en la mayoría de las areniscas y en ciertas calizas de naturaleza metamórfica y estratificada, es decir, en los mármoles.

Los minerales piritosos, expuestos a la acción de la intemperie, se oxidan transformándose en óxidos de hierro y ácidos sulfúrico y sulfuroso. Las superficies picadas que suelen apreciarse en los mármoles se debe a la acción del ácido sulfúrico secundario sobre los compuestos carbonatados.

El proceso químico de transformación, según SINGER y STUM (1), se debe a la oxidación 
de las piritas, repartidas homogéneamente por la masa, originando sulfato ferroso, $\mathrm{SO}_{4} \mathrm{Fe}$.

$$
\underset{\text { Pirita }}{\mathrm{SFe}}+\underset{\text { Oxigeno }}{2 \mathrm{O}_{2}} \rightarrow \underset{\text { Sulfato ferroso }}{\mathrm{SO}_{4} \mathrm{Fe}}
$$

En una segunda etapa el ion ferroso, $\mathrm{Fe}^{-}$, se combina con el oxígeno presente en el agua de lluvia o el vapor acuoso de la atmósfera, y se oxida a ion férrico, $\mathrm{Fe}^{-}$, y ácido sulfúrico, denominado secundario:

$$
\begin{aligned}
& 4 \mathrm{SO}_{4} \mathrm{Fe}+4 \mathrm{H}_{2} \mathrm{O}+\mathrm{O}_{2} \rightarrow 2 \mathrm{Fe}_{2} \mathrm{O}_{3}+4 \mathrm{SO}_{4} \mathrm{H}_{2} \\
& \text { Sulfato Agua Oxígeno Oxido Acido sulfúrico } \\
& \text { ferroso férrico }
\end{aligned}
$$

esta reacción tiene lugar en dos procesos simultáneos:

1)

2)

$$
\begin{aligned}
& 4 \mathrm{Fe}^{-}+3 \mathrm{O}_{2} \rightarrow 2 \mathrm{Fe}_{2} \mathrm{O}_{3} \\
& 4 \mathrm{SO}_{4}=+4 \mathrm{H}_{2} \rightarrow 4 \mathrm{SO}_{4} \mathrm{H}_{2}
\end{aligned}
$$

Antes de que se verifique la reacción 1), el ion ferroso, $\mathrm{Fe}^{-}$, puede desplazarse de su punto de origen y entonces el producto oxidado que origina se encuentra a cierta distancia de la localización primitiva.

Finalmente en una tercera etapa, el ion férrico, precipita en forma de hidróxido férrico amorfo

$$
\mathrm{Fe}_{2} \mathrm{O}_{3}+3 \mathrm{H}_{2} \mathrm{O} \rightarrow 2 \mathrm{Fe}(\mathrm{OH})_{3}
$$

que poico a poco cristaliza en un mineral de color ocre o pardo, llamado goetita y más raramente en un mineral rojo anaranjado denominado lepidocrocita.

La solubilidad del hidróxido férrico en el agua es muy pequeña $0,0005 \mathrm{mg} / \mathrm{l}$ a $\mathrm{pH}=5$, y menor a $\mathrm{pH}=7,0,000005 \mathrm{mg} / \mathrm{l}$. La formación de ácido sulfúrico secundario durante la meteorización de la pirita puede disminuir el $\mathrm{pH}$, llegando a adquirir el valor de $\mathrm{pH}=3$, en cuyo caso la solubilidad del hidróxido férrico es mucho mayor, $5 \mathrm{mg} / \mathrm{l}$. La gran movilidad del ion férrico, $\mathrm{Fe}^{-}$, en la disolución que ataca a la pirita, no permite su contacto con las porciones no oxidadas de los granos de aquélla, de ahí que se observen halos a distancias de hasta 5 y $7 \mathrm{~cm}$ del origen piritoso.

Si el hidróxido férrico precipita sobre un nódulo de pirita, su carácter fuertemente reductor, llega a transformar los iones férricos en ferrosos, formando sulfato ferroso de color verdoso.

En los estudios pétreas que he efectuado me ha parecido prudente determinar los contenidos de hierro en estado ferroso y férrico, y considerar la relación $\mathrm{Fe}^{-} / \mathrm{Fe}$ total, como un índice de la alteración de la piedra constituyente de un edificio.

\section{CARACTERISTICAS FISICAS DE LAS PIEDRAS}

\section{Porosidad accesible al agua}

Es la relación entre el volumen de poros accesibles al agua y el volumen aparente de la probeta.

La porosidad es una propiedad fundamental que influye en la durablidad. La mayoría 
de los procesos de alteración determinan un aumento de porosidad, mientras que los tratamientos de impregnación ocupan los poros y hacen disminuir la porosidad.

Este ensayo puede considerarse representativo de:

- La intensidad de la alteración.

- Evaluar la cantidad de poros ocupados con un tratamiento de impregnación.

- Evaluar el estado de una piedra de acuerdo con los criterios y especificaciones ASTM.

\section{Densidades real y aparente}

Estos valores se emplean para:

- Clasificar y valorar el estado de una roca según ASTM.

- Determinar la intensidad de la alteración.

- Observar el reemplazamiento de los poros por un impregnante.

\section{Absorción de agua}

Es la relación entre la masa de agua absorbida hasta saturación y la masa de la probeta.

Esta propiedad es análoga a la porosidad y sirve para evaluar los procesos de alteración. Su empleo fundamental es la clasificación de una roca según los criterios de ASTM.

\section{Resistencia mecánica a compresión}

Esta propiedad da una idea del comportamiento de una roca bajo la acción de esfuerzos exteriores, y puede considerarse como la resultante de las resistencias de sus componentes mineralógicos y de los enlaces cristalinos de unión.

Este comportamiento se expresa por la presión crítica que provoca la rotura o fisuración de la probeta.

La medida de la resistencia a compresión se utiliza para:

- Evaluar el estado de una piedra según las especificaciones ASTM.

- Juzgar la acción de un tratamiento de impregnación empleado para reforzar mecánicamente una roca.

La resistencia a compresión debe efectuarse sobre probetas desecadas y probetas saturadas y poder expresar la pérdida de resistencia en estado húmedo.

\section{ACCION DE LOS FACTORES EXTERNOS}

\section{La atmósfera}

La acción degradante de la capa atmosférica se debe a los compuestos de azufre, óxidos de nitrógeno y cloruros, considerados como impurezas o componentes minoritarios.

La presencia de los compuestos de azufre y nitrógeno se debe a los humos procedentes de los combustibles, tanto carbones como petróleos, si bien los carbones son los principa- 
les contaminantes, ya que disponen de un $8 \%$ de azufre; mientras que el gas natural no sobrepasa el valor del $2 \%$.

Las zonas industrializadas llegan a un consumo medio de $1 \mathrm{t}$ por persona y año, de este dato se deduce que se originan $0,6 \mathrm{~kg}$ de ácido sulfúrico por persona y año, cuando la humedad relativa es del $50 \%$, pero se eleva a $4,5 \mathrm{~kg}$ si la humedad relativa es del $98 \%$. Las calefacciones de las viviendas y oficinas durante el invierno incrementan las concentraciones de estos compuestos a niveles elevados.

El ion cloruro es un constituyente importante de la atmósfera, procede del mar, del desierto y de las industrias. Por acción catalítica puede transformarse en ácido clorhídrico que disuelve parcialmente las porciones carbonatadas de las rocas.

\section{La lluvia}

La composición del agua de lluvia está íntimamente ligada con la atmósfera local de la que procede, y su acción agresiva se debe a los iones captados durante su recorrido entre la nube y el suelo.

Recientemente los científicos WHITHEAD y FETH (2) distinguen entre "lluvia seca", "lluvia" y "precipitación".

La lluvia seca está formada por el conjunto de partículas sólidas procedentes de las capas bajas de la atmósfera que no han sido captadas por las gotas de lluvia, pero que caen a tierra junto icon ellas.

La "lluvia" está constituida por gotas de agua y partículas sólidas en suspensión, captadas durante su trayectoria.

Por precipitación se entiende el conjunto de las dos anteriores.

Los compuestos detectados en el agua de lluvia, mediante el análisis químico, indican con bastante claridad la atmósfera de donde proceden y su indudable origen marino. Las partículas secas nos refleja la naturaleza del polvo ambiental.

\section{La humedad}

La humedad que se observa en los muros de piedra de los edificios y monumentos procede de la atmósfera, la lluvia o el terreno.

Desde el punto de vista de agresión química no puede establecerse una ordenación peyorativa para éstas y deben considerarse todas con la misma importancia y peligrosidad.

\section{Humedad atmosférica}

Cuando existe un gradiente marcado de temperatura entre un muro y su entorno atmosférico, se depositan en la superficie fría de aquél cantidades considerables de agua, debido a la condensación del vapor. Estas cantidades nada despreciables se ignoran con bastante frecuencia y se desprecian en demasía.

En la fig. 1 se representa el contenido de agua, expresado en $\mathrm{g} / \mathrm{m}^{3}$ de aire seco y a la presión normal, en función de la temperatura ambiente y la humedad relativa.

Si se supone que el aire de la atmósfera se encuentra a $35^{\circ} \mathrm{C}$ y $60 \%$ de H.R., punto $A$, y se enfría hasta $20^{\circ} \mathrm{C}$, punto $A^{\prime}$, la H.R. irá aumentando y la condensación se inicia tan 
pronto como se allcanza el $100 \%$ de H.R., aproximadamente a los $25^{\circ} \mathrm{C}$. A $20^{\circ} \mathrm{C}$ se habrán condensado 6,5 $\mathrm{g}$ de humedad por cada $\mathrm{m}^{3}$ de aire.

En los templos y lugares públicos este tipo de humedad es de tener muy en cuenta, como vehículo de sales y otras sustancias perjudiciales.

Mediante el proceso de condensación expuesto, el agua depositada en la superficie de los muros puede introducirse en la piedra. Esta acción física está, sin duda, influida por la difusión de la humedad en el aire, las corrientes y otros factores.

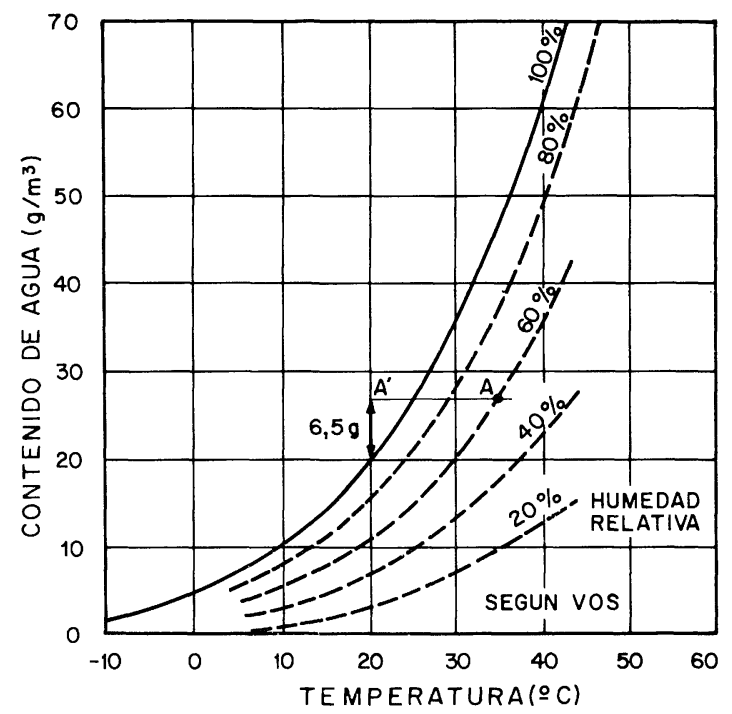

Gráfica 1

\section{Humedad de la lluvia}

Se debe a las lluvias y nieblas localizadas. Estudios experimentales han demostrado que el agua de lluvia no se introduce fácilmente en los muros de piedra, como se ha venido creyendo.

Generalmente las lluvias y las nieblas actúan de una forma muy intermitente y después de un período de humedad excesiva sucede otro de secado, que suele ser suficiente para eliminar la humedad depositada.

Los muros construidos con piedra arenisca o calizas porosas, suficientemente permeables, y que además están expuestas a este tipo de acción, pueden transmitir la humedad debida a la lluvia y nieblas, hacia zonas interiores del edificio.

\section{Humedad del terreno}

Proviene de las aguas freáticas y subálveas. Esta clase de aguas suele contener una cantidad de sales disueltas, siempre mayor que las aguas superficiales, debido a que transcurren lentamente entre partículas de minerales y rocas, favoreciendo el proceso de disolución.

El movimiento ascendente, debido al efecto capilar de los iones salinos, es un proceso continuo, tratando de llegar a las aberturas de los canalículos en la superficie de la piedra, lugar donde cristalizan. Si se trata de una sal muy soluble, no sólo cristalizan en la superficie, sino también en el interior de los canalículos en zonas próximas a la superficie.

La altura máxima que puede alıcanzar la humedad se hace patente por la presencia de eflorescencias de aspecto blanquecino o negruzco, dependiendo de su naturaleza.

La dinámica de la humedad, que es tanto como decir de los iones salinos, se rige por las reglas siguientes:

- En canalículos horizontales, cuyos extremos mantienen la misma presión y temperatura, la humedad condensada en su interior permanece en régimen estacionario.

- En canalículos de forma troncocónica, la humedad se desplaza hacia la zona estrecha.

- Cuando en un sistema poroso existen diferencias de temperatura, la humedad emigra 
a las zonas más frías. Generalmente en los muros de los edificios antiguos la zona interna es la más fría y, por tanto, en la mayoría de los monumentos, la humedad se desplaza desde el exterior al interior de la estructura.

- Las sales solubles contenidas en los bloques de piedra se desplazan hacia las caras exteriores, encontrándose en los $5 \mathrm{~cm}$ primeros los contenidos más elevados.

- Las sales más insolubles, yeso, sulfito cádcico y carbonato cálcico cristalizan en las zonas más próximas a la superficie, apreciándose el hecho notable que la cristalización es mayor en las áreas expuestas a la luz, que en las oscuras. Las sales más solubles, como los cloruros y sulfatos alcalinos, permanecen más al interior.

- El camino recorrido por la humedad y las sales en dirección horizontal es superior al vertical. Este resultado, en apariencia sorprendente, no lo es tanto puesto que el valor de la tensión capilar es independiente de la posición del tubo y, por consiguiente, cuando se encuentra en posición horizontal, favorece el paso del fluido, mientras que en posición vertical actúa únicamente la fuerza de cohesión de las moléculas. La experiencia demuestra que, aproximadamente, ell camino recorrido es doble en sentido horizontal que en vertical.

\section{Acción solar}

Por simples ciclos de empapado-secado a temperatura constante, una roca experimenta acciones expansivas. La aoción calórica de los rayos solares juega un papel importante en la alteración y destrucción de las piedras.

Se ha comprobado que la temperatura alcanzada por un material en la superficie es aproximadamente un $30 \%$ más elevada que la máxima del medio ambiente que le rodea; naturalmente que las tonalidades de las rocas intervienen de forma primordial: los materiales pétreos oscuros, tales como gabros y mármoles negros adquieren temperaturas de un $60 \%$ más elevada que la del aire circundante.

\section{FORMACIONES SALINAS}

\section{Las eflorescencias}

Están formadas por depósitos salinos, como manchas, salpicaduras y rebordes sobre los materiales de construcción. Su formación se debe a un proceso de cristalización en la superficie de los sistemas capilares abiertos y de las sales solubles transportadas por la humedad. No suelen causar daños al material, pero influyen en sus cualidades estéticas. Por otra parte, las formaciones salinas superficiales proporcionan información acerca de la emigración salina y del nível superior alcanzado por la humedad.

\section{Las subesflorescencias}

En las zonas urbanas húmedas y marítimas suele darse el fenómeno de las subesflorescencias, debido a que las sales muy solubles, cloruros y sulfatos alcalinos, cristalizan antes de llegar a la superficie, o sea, por debajo de ésta originando una zona de alteración, constituida por sustancias pulverulentas y poco adherentes. Con el tiempo, relativamente corto, esta especie de costra pierde su soporte y se desprende en forma de cascarilla. Las subesflorescencias son más temibles que las eflorescencias, pues mientras éstas son visibles, las subesflorescencias no se manifiestan hasta el desprendimiento del material. 


\section{Proceso salino}

Las sales durante su proceso de cristalización originan acciones expansivas, debidas a presiones de cristalización y a la higrocopicidad de las sales.

La presión de cristalización se produce durante la formación cristalina en el interior de los poros capilares, que pueden llegar a originar su rotura.

CORRENS (3) ha establecido una expresión basada en el Principio de RIECKE, según la cual un cristal sometido a una presión presenta una solubilidad mayor que cuando no experimenta tensión alguna:

$$
P=\frac{R \cdot T}{V_{\mathrm{s}}} \ln \frac{C}{C_{\mathrm{s}}}
$$

en la que:

$P=$ Presión de orecimiento en atm.

$R=$ Constante de los gases $=0,082$ litros $\cdot$ at $/{ }^{\circ} \mathrm{K} \cdot \mathrm{Mol}$.

$T=$ Temperatura en ${ }^{\circ} \mathrm{K}$.

$V_{\mathrm{s}}=$ Volumen molecular de la sal en estado sólido.

C = Concentración del soluto durante la cristalización.

$C_{\mathrm{s}}=$ Concentración del soluto a saturación.

Se sobreentiende que es condición indispensable para que tenga lugar la cristalización, que la disolución esté sobresaturada. Ver grafica n. $^{\circ} 2$.

El investigador MULLIN (4) ha relacionado la temperatura $T$ con la proporción $C / C_{\mathrm{s}}$.

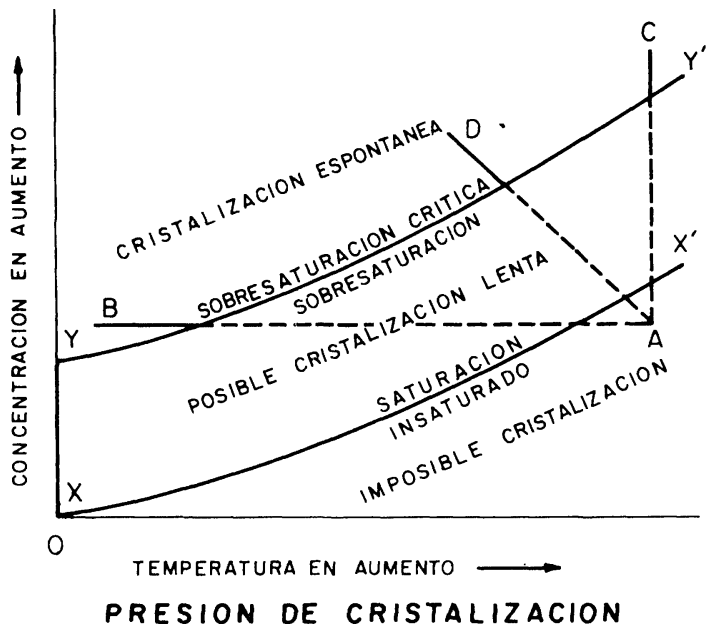

Gráfica 2

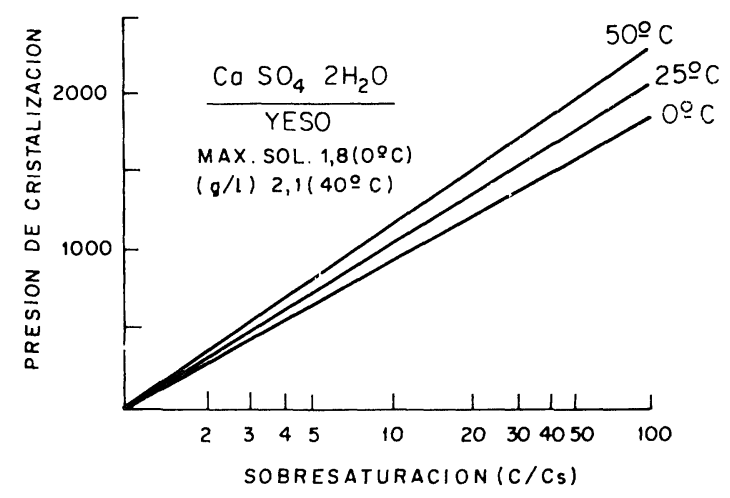

Gráfica 3

Algunas sales son capaces de hidratarse y deshidratarse de acuerdo con las condiciones ambientales de temperatura y humedad relativa, es decir, son higroscópicas. Este fenómeno lleva implícito una absorción de agua y un aumento de volumen, originando presiones en las paredes de los poros y capilares. 


\section{CARACTERISTICAS PARA LA EvALUACION DE LAS HUMEDADES}

\section{Grado de saturación}

Es el volumen de agua presente en los poros de un material después de su inmersión completa a la presión atmosférica durante un tiempo definido en relación con el volumen total de poros accesibles al agua, expresado en tanto por ciento.

Se utiliza para evaluar la resistencia al hielo y controlar la eficacia de un tratamiento de estanquidad o hidrófugo.

\section{Ensayo de mojabilidad}

Consiste en medir el tiempo de absorción de una cantidad de agua limitada y definida, que se ha depositado sobre la superficie del material.

Naturalmente que el tiempo de absonción es mayor para las piedras sanas y aquellas que hayan sido sometidas a procesos de hidrofugación.

Las superficies bien hidrofugadas no absorben agua; en este caso el tiempo necesario para la desaparición del agua depositada es idéntico al tiempo de evaporación. Los tiempos de evaporación más cortos indican un aumento de la porosidad, debido a una alteración $o$ higroscopicidad.

Este ensayo es muy fácil de efectuar, pero mide muy bien la moldificación de las propiedades de la superficie de la piedra, particularmente adecuado para medir el grado de hidrofugación superficial, incluso la profundidad de penetración del tratamiento, mediante ensayos repetitivos de mojabilidad y abrasión.

\section{Dilatación lineal por absorción de agua}

Es el aumento de longitud experimentado por una probeta prismática, debido a la absorción de agua.

Se emplea para evaluar determinados tipos de degradación, tales como la alteración de areniscas que contienen hierro o arcillas expansivas.

\section{Absorción capilar}

Es la cantidad de agua absorbidia durante un cierto tiempo por una superficie de una muestra cúbica de piedra, previamente desecada.

Se acostumbra a exponer mediante un diagrama, expresando la masa de agua absorbida por unidad de superficie en función del tiempo, $t^{0,5}$ obteniéndose una recta. El valor de la pendiente geométrica de la recta se denomina "coeficiente de absorción".

Mide la eficacia de los tratamientos hidrófugos e impermeables.

\section{Curva de evaporación}

Los procesos que regulan el tiempo de secado de las piedras en los monumentos son muy complejos ya que dependen del contenido de agua inicial, de su distribución en la masa, de la forma de los elementos y de las condiciones ambientales. 
El ensayo consiste en disponer de los valores precisos para establecer un diagrama de evaporación, exponiendo el contenido del agua actual en función del tiempo. Conviene indicar el $\%$ de agua evaporada al cabo de 5 y 24 horas. Ver gráfica 4.

\begin{tabular}{|c|c|}
\hline $\begin{array}{c}\text { Tiempo de } \\
\text { evaporación } \\
\text { horas }\end{array}$ & $\begin{array}{c}\text { Contenido } \\
\text { de agua } \\
\text { actual m } \mathrm{m}^{3} / \mathrm{m}^{3}\end{array}$ \\
\hline 0 & 0,075 \\
1 & 0,074 \\
2 & 0,072 \\
3 & 0,069 \\
4 & 0,067 \\
5 & 0,065 \\
8 & 0,061 \\
24 & 0,049 \\
\hline
\end{tabular}

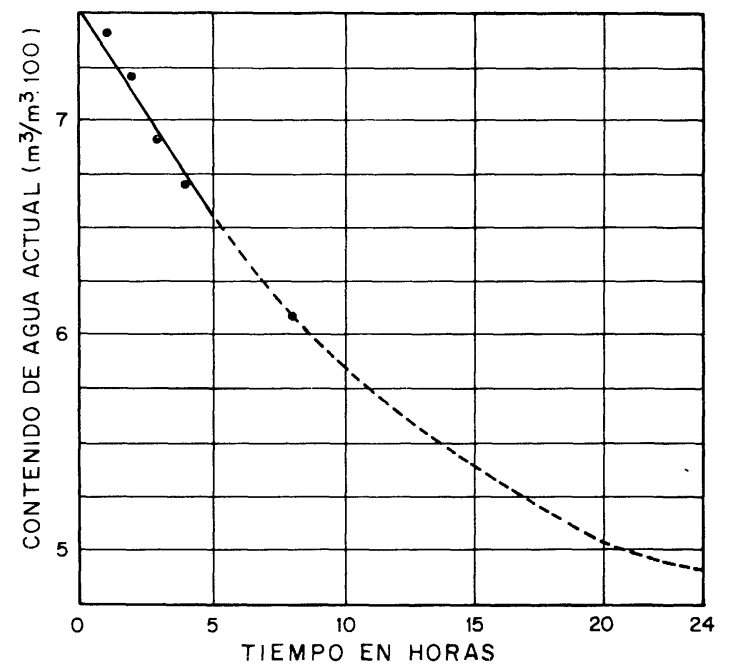

Gráfica 4

Coeficiente de secado hasta 6 horas $=0,01 \mathrm{gr} / \mathrm{cm}^{2} / \mathrm{h}$. Secado 5 horas $=19 \%$.

Secado 24 horas $=35 \%$.

\section{EVALUACION DE LA SALINIDAD EN UNA ROCA}

Consiste en conocer el contenido de iones solubles, que contiene la piedra en su interior, así como su posible composición.

A este fin se trata una cierta cantidad de la piedra, previamente molturada con el doble de su peso de agua destilada, durante 24 horas, y en el extracto acuoso se determinan los iones siguientes:

- Residuo salino a $105^{\circ} \mathrm{C}$, expresado en $\mathrm{mg} / \mathrm{l}$.

- Contenido de sulfatos, expresados como $\mathrm{SO}_{4}=\mathrm{en} \mathrm{mg} / \mathrm{l}$.

- Contenido de cloruros, expresados como $\mathrm{Cl}^{-}$en $\mathrm{mg} / \mathrm{l}$.

- Contenido de calcio, expresado como $\mathrm{Ca}$ en $\mathrm{mg} / \mathrm{l}$.

- Contenido de magnesio, expresado como $\mathrm{Mg}$ en $\mathrm{mg} / \mathrm{l}$.

- Contenido de carbonatos y bicarbonatos, expresados como $\mathrm{CO}_{3}=$ y $\mathrm{CO}_{3} \mathrm{H}^{-}$respectivamente en $\mathrm{mg} / \mathrm{l}$.

- Contenido de iones alcalinos, $\mathrm{Na}^{+}$y $\mathrm{K}^{+}$, en $\mathrm{mg} / \mathrm{l}$.

Mediante un estudio de las concentraciones anteriores en miliequivalentes se pueden intuir las sales que contiene el elemento pétreo estudiado.

La presencia de iones cloruro y sulfatos alcalinos nos indican la posible formación de subesflorescencias y costras del temido mal de la piedra.

El carácter marino o costero se pone de manifiesto por la presencia de sulfato o cloruro magnésico. 
En realidad la interpretación analítica debe dejarse en manos de un experto, que la enjuiciará de acuendo con el tipo de piedra estudiada, así como de las circunstancias ambientales y de situación de la piedra.

\section{Resistencia a la cristalización}

Se realiza mediante la inmersión parcial de probetas en una disolución de $\mathrm{SO}_{4} \mathrm{Na} .10 \mathrm{H}_{2} \mathrm{O}$ a la temperatura de $33^{\circ} \mathrm{C}$. La disolución asciende por capilaridad y se evapora en la superficie superior de la probeta, provocando un aumento de volumen debido a la cristalización de las sales.

Este ensayo acostumbra a hacerse con probetas tratadas y no tratadas y es en realidad una prueba acelerada que permite evaluar la resistencia a la acción de las sales.

Este ensayo es muy útil para indicar el comportamiento de la zona superficial e interior y en especial de la región de contacto entre ambas.

\section{Comportamiento a la acción de las heladas}

Se pone de manifiesto mediante ciclos sucesivos de "hielo-deshielo". Estableciéndose ensayos comparativos de piedras tratadas y no tratadas. La acción se estima por examen ocular, por medición del volumen aparente y por medida de resonancia longitudinal.

\section{PLAN DE ACTUACION PARA EL ESTUdio de LAS zONAS PETREAS DE UN MONUMENTO}

En primer lugar proveerse de un plano, en planta y alzado del edificio, en el cual se indicarán las distintas zonas pétreas o de materiales pétreos diversos, estimados por examen visual o por constancia en datos históricos en los archivos de su construcción. Los monumentos suelen contener piedras de diferentes tipos petrográficos o que presentan distintos grados de alteración visual para un mismo tipo.

Cada zona pétrea debe marcarse y situarse perfectamente en el plano mediante distintos colores y tonalidades.

Cuando no se aprecian variaciones en la petrografía o en los estados de alteración, se toman muestras individuales con un cierto criterio arquitectónico o de exposición a los distintos agentes atmosféricos.

Es muy conveniente la colaboración de un experto en petrografía para efectuar la toma de muestras.

La cantidad y dimensiones de la probeta deben ser previamente establecidas para la ejecución de los ensayos previstos con una precisión aceptable.

En muchas ocasiones la cantidad de muestra a tomar viene determinada por las necesidades técnicas y petrográficas junto con las artísticas que permitan conservar los valores artísticos y culturales del monumento, de forma que las muestras tomadas causen el menor deterioro material posible. En el Anejo se expone el Cuadro 1 en el que se indica el orden para efectuar los ensayos con el mínimo material preciso.

\section{EVALUACION DE LOS RESULTADOS}

A partir de los resultados obtenidos en los ensayos realizados se calculan los valores me- 
dios, caso de ser significativos, así como otros datos estadísticos, cuyas series de valores diferentes pueden representar a una zona pétrea o a la totalidad del monumento.

Una evaluación absoluta es muy difícil de especificar, pero las Normas ASTM, los datos bibliográficos y la experiencia de laboratorio, han permitido establecer las especificaciones que se indican en el Anejo, Cuadro 2.

\section{EXPERIENCIA FINAL}

Independientemente de los resultados obtenidos en los ensayos de valoración, la mayoría de los daños importantes que afectan a los monumentos atañen a su estructura, ya que aquellos que interesan a los motivos decorativos, exteriores o interiores, siempre son más fáciles de restaurar, aunque no siempre sean los más económicos.

Las alteraciones que produce la contaminación ambiental, a través de mi experiencia personal, parece que influye más en los motivos ornamentales exteriores. Los daños estructurales se deben principalmente a reacciones intrínsecas de la piedra para su degradación y la acción de las distintas humedades.

Como dato curioso, pero repetitivo, debo exponer que cuando se consultan los datos arquitectónicos del edificio que se analiza, suele encontrarse que arquitectos de épocas pasadas habían detectado daños análogos a los que actualmente se aprecian, y que incluso habían utilizado los medios técnicos de su época para corregirlos. El análisis detenido de aquellos medios con la luz de los conocimientos actuales puede muchas veces ser la solución del problema planteado.

Así en los problemas de la Cúpula de La Clerecía de Salamanca, ya los había detectado el conocido arquitecto Ventura Rodríguez, quien estimó que los materiales pétreos empleados no eran los adecuados para el enorme peso que tenía la cúpula y el cupulino o linterna. La enorme masa de ambos tiende a reventar el tambor de la cúpula. La reparación en aquella época consistió en zunchar mediante elementos metálicos o cadenas, que a lo largo del tiempo no ejercieron acción alguna.

Mediante los estudios que realicé se comṕrobó que estaba construido, el citado tambor, con una piedra arenisca que manifestaba una elevada absorción de agua y deformabilidad frente a la humedad, cualidades ambas que hacían perder a la piedra el $75 \%$ de su resistencia a compresión en estado saturado. Los zunchos metálicos que habían dispuesto no hacían más efecto que una acción cortante en la piedra sin impedir su desplome.

En la Catedral de León se comprobó que, el problema de inestabilidad, se debía al mal estado de sus arbotantes, como consecuencia de algunos elementos pétreos que no eran suficientes para transmitir las cargas del edificio. Este problema se observó hacía ya 100 años, ordenándose entonces la sustitución de los elementos deficientes por otros sanos. Recientemente he podido comprobar que los arbotantes están construidos con areniscas muy heterogéneas con elevados contenidos de hierro ferroso en estado de oxidación a férrico $\mathrm{y}$, por consiguiente, con un grado potencial de alteración. Un estudio más detallado de sus propiedades mecánicas informó al ingeniero de su deficiente estado desde el punto de vista estructural.

En ninguno de estos dos casos, y podría citar más, ha jugado la contaminación ambiental el papel demoníaco que se le atribuye. Es evidente que no es beneficiosa, pero no es la única causa de la pérdida del patrimonio cultural. 
No debe pensarse, pero se ha pensado, que el Claustro Románico del Monasterio de Silos, conforme he leído no hace mucho, es una víctima de la contaminación, cuando está enclavado en un entorno olvidado de Castilla. Qué ojos polarizados le han contemplado que no han sido capaces de advertir la naturaleza de sus piedras y el terreno que le sustenta.

Independientemente de los problemas estructurales, los monumentos sufren las alteraciones de tipo ornamental, caso del Claustro que acabo de citar, que aunque no son objeto de este artículo son muy importantes, ya que el público los descubre más rápidamente; pero es cierto, que los remedios están más estudiados y, en último caso, cabe la reconstrucción del modelo.

Me parece fundamental convencernos que los monumentos pertenecen a cada zona y que han de ser ellos sus restauradores y conservadores principales. La Catedral de Colonia es todavía un edificio inacabado, con un equipo técnico de construcción que no sólo restaura, sino que va añadiendo motivos, gárgolas, efigies e imágenes con temas modernos que atañen a la historia actual de la ciudad.

La conservación del patrimonio artístico, tanto a nivel regional como nacional, constituye un reto para la saciedad actual, que debe conservar los valores culturales frente a la acción devoradora del tiempo.

\section{B I B L I O G R A F I A}

(1) P. C. Singer y W. Stumm: Science, n. 167. Pág. 1.121 (1970).

(2) H. C. Whitehead y J. H. FETH: Jourrıal Geophisical Research. Pág. 3.319 (1964).

(3) C. W. Correns: Discussions of the Faraday Society. Pág. 267 (1949).

(4) J. W. Mullis : Crystalization. London. Butterworths. Pág. 268 (1961). 


\section{DOCUMENTACION ANEJA}

\section{CUADRO 1}

Plan de ensayos y tipos de probetas para cada "zona pétrea"

Se precisan:

15 probetas cúbicas de $5 \times 5 \times 5 \mathrm{~cm}^{3}$.

5 probetas prismáticas de $2,5 \times 2,5 \times 25 \mathrm{~cm}^{3}$.

2 porciones no inferiores cada una a $300 \mathrm{gr}$, encerrados perfectamente en una bolsa de plástico, para determinar el Contenido Actual de Humedad.

Sobre 5 probetas de $5 \times 5 \times 5 \mathrm{~cm}^{3}$ se efectúan los ensayos relacionados por el orden indicado:

- Porosidad accesible al agua.

- Densidades real y aparente.

- Absorción de agua.

- Coeficiente de saturación.

- Curva de evaporación.

- Resistencia a compresión estado saturado.

Sobre otra serie de 5 probetas de $5 \times 5 \times 5 \mathrm{~cm}^{3}$.

- Absorción por gotas (se desecan y).

- Resistencia a compresión en estado seco.

- Análisis petrográfico elemental

- Contenido de sales solubles

- Compues os de hierro y piritas

Sobre porciones procedentes del ensayo de resistencia en estado seco.

Sobre otra serie de 2 probetas de $5 \times 5 \times 5 \mathrm{~cm}^{3}$ :

- Succión capilar.

- Resistencia a a la cristalización.

Solbre otra serie de 3 probetas de $5 \times 5 \times 5 \mathrm{~cm}^{3}$ :

- Ensayo de heladicidad.

Sobre la serie de 5 probetas de $2,5 \times 2,5 \times 25 \mathrm{~cm}^{3}$ :

- Dilatación lineal por absorción de agua. 


\section{CUADRO 2}

Especificaciones que deben satisfacer las rocas aptas para edificación

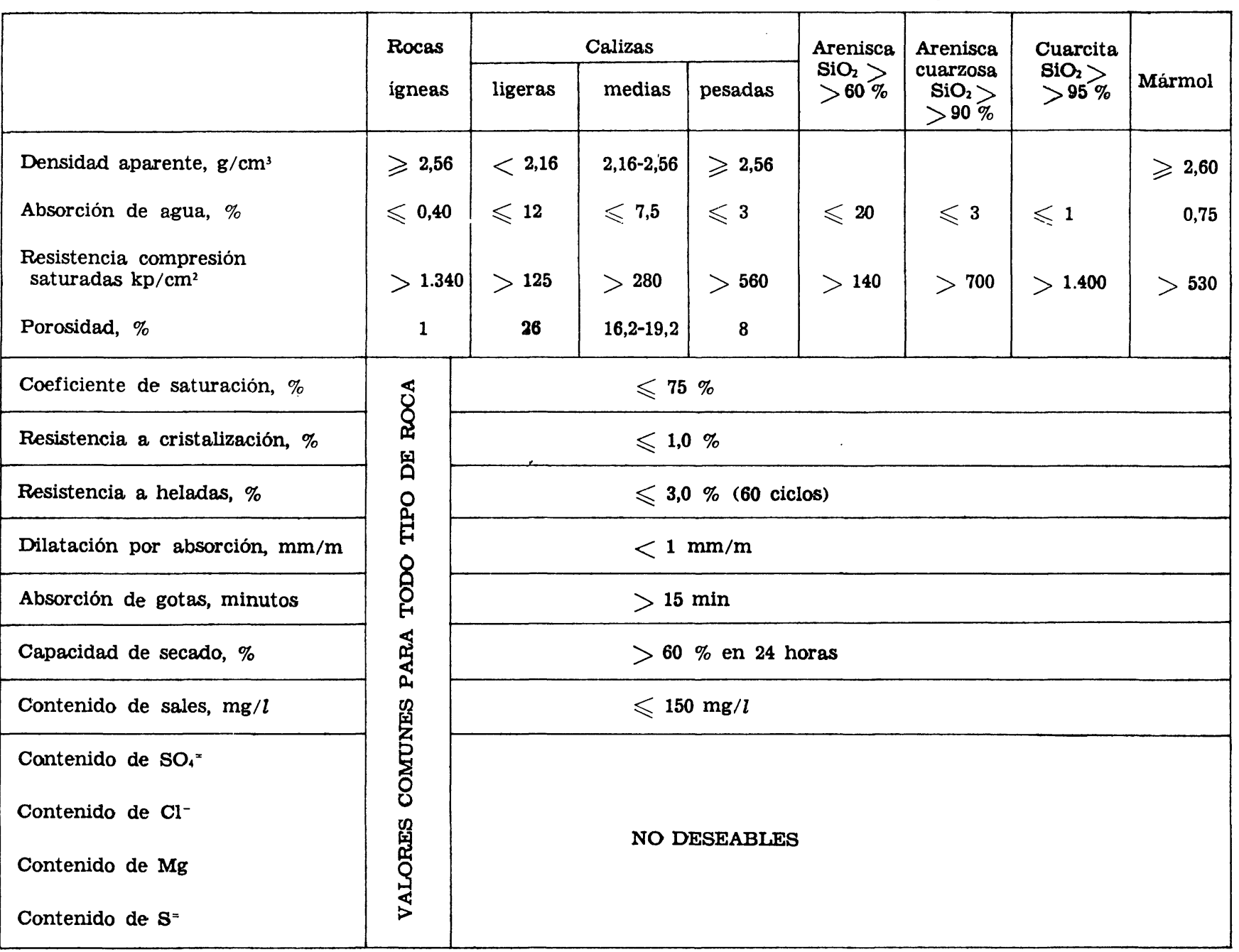

